\title{
Adaptation of myocardial blood flow to increased metabolic demand is not dependent on endothelial vasodilators in the rat heart
}

\author{
C P Tiefenbacher, H Tillmanns, F Niroomand, R Zimmermann, W Kübler
}

\begin{abstract}
Objective-To investigate the role of endothelial vasodilating factors in adaptation of myocardial blood flow to increased metabolic demands.

Design-Alterations in the effects of endothelium dependent (acetylcholine) and independent (sodium nitroprusside) vasodilators and the $\beta_{1}$ receptor agonist dobutamine were studied after inhibition of endothelium derived relaxing factor (EDRF) with $\mathbf{L}-\mathrm{N}^{\mathrm{G}}$-nitro-arginine methyl ester (L-NAME), prostanoid synthesis with indomethacin, and ATP sensitive potassium channels with glibenclamide.
\end{abstract}

Experimental animals-Female Wistar rats, in situ perfused heart.

Main outcome measures-Myocardial blood flow $\left(\mathrm{H}_{2}\right.$ clearance); systolic fractional thickening (pulsed Doppler); mean arterial blood pressure.

Results-L-NAME reduced myocardial blood flow by 58 (12)\% (mean (SD), P < $0 \cdot 001)$ and systolic thickening fraction (FT) by 36 (9)\% (P < 0.05). These effects were significantly reversed by administration of L-arginine but not D-arginine. Pretreatment with L-NAME inhibited the increase in myocardial blood flow caused by acetylcholine (control: +42 (9)\%; LNAME: -29 (7)\%, P < 0.001) but did not affect the increase in myocardial blood flow caused by sodium nitroprusside (control: +44 (5)\%; L-NAME: +34 (10)\%, NS). Pretreatment with L-NAME did not change the effect of dobutamine on myocardial blood flow (+61 (3)\%) and FT $(+32(8) \%)$ compared with baseline values $(\mathbf{P}<0.001)$. Neither pretreatment with indomethacin nor with glibenclamide reduced the dobutamine induced increase in myocardial blood flow.

Conclusions-Inhibition of EDRF, prostanoid synthesis, and ATP sensitive potassium channels did not reduce the vasodilator reserve during increased metabolic demands induced by $\beta_{1}$ adrenergic stimulation. Therefore, adaptation of myocardial blood flow to increased metabolic demands is independent of endothelial relaxing factors in the rat heart.

(Heart 1997;77:147-153)

Keywords: myocardial blood flow; myocardial function; endothelial vasodilating factors; coronary reserve
Vascular endothelium is an active regulator of vascular tone through its release of vasoactive substances. Known endothelial vasodilators are the endothelium derived relaxing factor (EDRF), prostaglandins (mainly prostacyclin), and the endothelium derived hyperpolarising factor (EDHF). ${ }^{12}$

EDRF, identified as nitric oxide (NO), ${ }^{3}$ is synthesised from the guanidino terminus of $\mathrm{L}$ arginine. ${ }^{4}$ The synthesis can be competitively inhibited by arginine analogues, such as $\mathrm{L}_{-} \mathrm{N}^{\mathrm{G}}$ nitro-arginine methyl ester (L-NAME), ${ }^{56}$ and this inhibition can be reversed by the administration of $\mathrm{L}$-arginine, but not $\mathrm{D}$-arginine. ${ }^{6}$

Prostacyclin $\left(\mathrm{PGI}_{2}\right)$, another endothelial vasodilator, is synthesised from arachidonic acid, ${ }^{7}$ mainly in endothelial cells. The key enzyme for the synthesis of $\mathrm{PGI}_{2}$, cyclooxygenase, can be inhibited by indomethacin. ${ }^{8}$

The endothelium derived hyperpolarising factor $^{2}$ has not yet been identified, though it might act by opening potassium channels, for example ATP dependent potassium channels. ${ }^{9}$ Opening of these latter channels is known to be blocked by glibenclamide. ${ }^{10}$

Several investigators have shown an attenuation of endothelium dependent vasodilatation after ischaemia ${ }^{112}$ and in diseases such as hypertension, atherosclerosis, or diabetes mellitus. ${ }^{13}$ Furthermore, vascular relaxation by endothelium dependent vasodilators has been shown to be reduced both in coronary arteries and in coronary arterioles, starting early in the development of atherosclerosis. ${ }^{14}$ This may result in a diminished vasodilating capacity of these vessels, for example during exercise, leading to angina on effort. Furthermore, endothelial dysfunction may contribute to the development of arterial spasm. ${ }^{15}$ The impact of endothelial relaxing factors compared with non-endothelium-derived vasodilators such as adenosine ${ }^{16}$ or growth factors ${ }^{17}$ on coronary resistance has not been determined, though it appears to be important for the understanding of coronary autoregulation and for the development of new treatments for coronary artery disease.

The aim of this study was therefore to investigate myocardial vasodilating capacity during increased metabolic demands after inhibition of the endothelial relaxing factors EDRF, prostaglandins, and ATP sensitive potassium channels.

\section{Methods}

ANIMAL PREPARATION

Female Wistar rats of 215 (SD 30) g body weight (bw) were anaesthetised with intraperi- 
toneal barbiturate (Inactin Byk-Gulden, 0.1 $\mathrm{mg} / 100 \mathrm{~g}$ bw intraperitoneally) and artificially ventilated (small animal ventilator, Harvard) with a volume of $2-3 \mathrm{ml}$ at a rate of $60-75$ strokes $/ \mathrm{min}$. Body temperature was maintained at $37^{\circ} \mathrm{C}$ using a heated operating table. The carotid artery was cannulated for continuous measurement of systemic blood pressure (Statham pressure transducer). The jugular vein was cannulated to allow administration of fluid and drugs. The heart was exposed by removing an oblong portion of chest wall and sternum.

DETERMINATION OF MYOCARDIAL BLOOD FLOW Myocardial blood flow was measured by the hydrogen $\left(\mathrm{H}_{2}\right)$ clearance technique using platinum electrodes inserted into the myocardial tissue for measuring tissue $\mathrm{H}_{2}$ pressure $\left(\mathrm{PH}_{2}\right)$. The basic theory of determining tissue blood flow by inert gas clearance and the applicability of $\mathrm{H}_{2}$ as an indicator has been described earlier. ${ }^{18}$ In brief, the target tissue is saturated with hydrogen at a constant $\mathrm{PH}_{2}$ by adding a constant fraction of $\mathrm{H}_{2}(30 \%)$ to the inspired air. After $\mathrm{H}_{2}$ is removed from the inspired air, the tissue $\mathrm{H}_{2}$ is washed out by $\mathrm{H}_{2}$-free blood, yielding an exponential concentration decline in tissue. The tissue blood flow $(\mathrm{ml} / \mathrm{min} / \mathrm{g})$ is derived from the half time of $\mathrm{PH}_{2}$ decay as tissue blood flow $=\ln 2 / t_{1 / 2}$. The exponential fit of the measured $\mathrm{PH}_{2}$ curve for determining flow was done with a computer aided device. The $\mathrm{H}_{2}$ curves deviated slightly from a monoexponential shape only at the beginning $(100-80 \%)$ and at the end (5-0\%). Therefore, for evaluation of myocardial blood flow, only the mid portion of the curves $(80-10 \%)$ was used. The logarithmic regression coefficient of all curves was $>0.98$.

The electrodes used in this study were made from $50 \mu \mathrm{m}$ epoxide insulated platinum wires with a 300-500 nm non-insulated $\mathrm{PH}_{2}$ sensing tip. The electrodes were inserted into the myocardium for approximately $2 \mathrm{~mm}$ and polarised against a rectally positioned silver/silver chloride reference electrode by $-300 \mathrm{mV}$.

The $\mathrm{H}_{2}$ clearance method was validated in isolated perfused rat hearts (Langendorff model). At different perfusion rates, reliable values could be obtained for myocardial blood flow with the clearance technique. In the in situ perfused rat heart model, measurements could be reliably reproduced with $5-10 \%$ changes in myocardial blood flow. ${ }^{19}$

\section{DETERMINATION OF REGIONAL LEFT \\ VENTRICULAR FUNCTION}

Regional left ventricular function was assessed by determination of myocardial systolic thickening fraction (FT) using the pulsed Doppler technique with a single epicardial transducer (Crystal Biotech) as described previously. ${ }^{20}$ The Doppler crystal was placed on the left ventricular wall and sutured to the epicardium with a fine stitch (prolene, $7 \cdot 0$ ). Myocardial wall thickening was evaluated by integrating the velocity of myocardial layers passing through a sample volume at a selected depth, which was determined by characteristic acoustic signals and by characteristic echo signals on an oscilloscope. External trigger for processing of the Doppler signal was obtained from an electrocardiogram. Myocardial thickening fraction was then estimated by dividing systolic excursion by the sample volume. Measurements could be reliably reproduced with $5-10 \%$ changes of myocardial thickening fraction.

\section{EXPERIMENTAL PROTOCOL}

Six series of experiments were performed. In all series, myocardial blood flow, systolic thickening fraction, mean arterial blood pressure, and heart rate were determined under baseline conditions and $30 \mathrm{~s}$ after infusion of acetylcholine $(0.09 \mathrm{~g} / \mathrm{kg}$; Merck, Darmstadt, Germany), sodium nitroprusside $(0.15 \mathrm{~g} / \mathrm{kg}$; Merck), and dobutamine $(0.09 \mathrm{mg} / \mathrm{kg}$; Lilly, Germany). The $30 \mathrm{~s}$ interval was chosen to prevent alterations of myocardial blood flow by systemic effects of the vasodilators, since the administration of the vasodilating agents acetylcholine and sodium nitroprusside causes a transient brief (15-20 s) decrease in mean arterial pressure due to systemic vasodilatation.

Series I: control group ( $\mathrm{n}=8)-$ Haemodynamic measurements and FT were determined continuously and myocardial blood flow was determined under baseline conditions as well as $30 \mathrm{~s}$ after application of acetylcholine, sodium nitroprusside, and dobutamine.

Series II: L-NAME group $(\mathrm{n}=6)$-After six control measurements of myocardial blood flow, FT, and mean arterial pressure, LNAME $(10 \mathrm{mg} / \mathrm{kg}$; Sigma Chemical Co, St Louis, MO, USA) was given. Thirty minutes after addition of L-NAME, acetylcholine, sodium nitroprusside, and dobutamine were subsequently given and measurements were repeated $30 \mathrm{~s}$ after application of each substance.

To assess the selectivity of inhibition of nitric oxide production by L-NAME, L- or Darginine $(100 \mathrm{mg} / \mathrm{kg}$ bolus followed by 100 $\mathrm{mg} / \mathrm{kg} / \mathrm{h}$ intravenous infusion) was infused in an additional six rats $20 \mathrm{~min}$ after the administration of L-NAME.

To rule out a change of the metabolic cost of dobutamine after pretreatment with LNAME, the double product was calculated as a measurement of cardiac work under the influence of dobutamine before and after LNAME.

Series III: indomethacin group $(\mathrm{n}=6)$, series IV: indomethacin and L-NAME group $(\mathrm{n}=6)$, series $V$ : glibenclamide group $(\mathrm{n}=6)$, and series VI: glibenclamide $+L-N A M E$ group $(\mathrm{n}=6)-$ After six control measurements, indomethacin $(5 \mathrm{mg} / \mathrm{kg}$, series $\mathrm{III})$, indomethacin $+\mathrm{L}$ NAME (series IV), glibenclamide $(0.5 \mathrm{mg} / \mathrm{kg}$ bolus followed by $0.5 \mathrm{~g} / \mathrm{kg} / \mathrm{min}$ continuous intravenous infusion, series $\mathrm{V}$ ), and glibenclamide in addition to L-NAME (series VI) were given intravenously. Haemodynamic measurements and FT were recorded continuously and myocardial blood flow was deter- 
Figure 1 Systolic thickening fraction (FT; \%) under baseline conditions and after application of dobutamine application of dobutamine the control group $(n=8)$ at right, data on the $L-N A M E$ pretreated group $(n=6)$. Error bars = $S D, n=8$ experiments. ${ }^{\star} P<0.05$ v baseline; $+P<0.05 v$ pretreatment with $L-N A M E$.

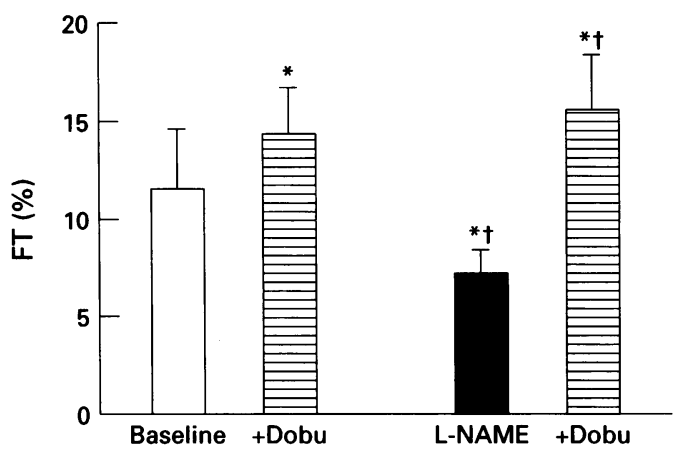

mined $30 \mathrm{~s}$ after bolus application of acetylcholine, sodium nitroprusside, or dobutamine, respectively, as in series I and II.

\section{STATISTICAL ANALYSIS}

The data are expressed as mean (SD). To test for significance between means, the (repeated) analysis of variance followed by the Bonferoni $t$ test was used. For all tests, a probability value of $P<0.05$ was considered statistically significant.

\section{Results}

SERIES I (CONTROL GROUP)

Under baseline conditions, myocardial blood flow was $3.8(0.2) \mathrm{ml} / \mathrm{g}$ (mean (SD)), FT was $11.5(0.8) \%$, and mean arterial pressure was $120(8) \mathrm{mm} \mathrm{Hg}$.
After bolus application of acetylcholine, myocardial blood flow increased to $5.4(0.5)$ $\mathrm{ml} / \mathrm{min} / \mathrm{g}(\Delta=+42(9) \%, \mathrm{P}<0.001)$; acetylcholine had no significant effect on FT (11.8 $(0.6) \%)$ and mean arterial pressure (110 (8) $\mathrm{mm} \mathrm{Hg}$ ).

Bolus administration of sodium nitroprusside increased myocardial blood flow to $5 \cdot 5$ $(0.3) \mathrm{ml} / \mathrm{min} / \mathrm{g}(\Delta=+44(5) \%, \mathrm{P}<0.001)$ whereas FT $(11.5(0.7) \%)$ and mean arterial pressure $(114(9) \mathrm{mm} \mathrm{Hg}$ ) were unaffected.

After bolus administration of dobutamine, myocardial blood flow and FT increased significantly: myocardial blood flow to $6(0.2)$ $\mathrm{ml} / \mathrm{min} / \mathrm{g}(\Delta=+57(4) \%)$ and FT to $14 \cdot 4$ $(0.9) \%(\Delta=+26(11) \%)$. Mean arterial pressure was also increased to 135 (9) $\mathrm{mm} \mathrm{Hg}$ (fig 1, tables 1-3).

SERIES II (L-NAME GROUP)

Following intravenous infusion of L-NAME, a significant reduction in myocardial blood flow and FT was observed (myocardial blood flow: $1.6(0.2) \mathrm{ml} / \mathrm{min} / \mathrm{g}, \Delta=-58(12) \%$; FT: $7 \cdot 3$ $(0.4) \%, \Delta=-36(9) \%)$. In contrast, mean arterial pressure increased to 150 (5) $\mathrm{mm} \mathrm{Hg}$ $(\Delta=+25(5) \%)$

The effects of L-NAME on myocardial blood flow, FT, and mean arterial pressure were not significantly altered $30 \mathrm{~min}$ after continuous intravenous administration of $\mathrm{D}$ arginine (myocardial blood flow: $1.7(0.3)$ $\mathrm{ml} / \mathrm{min} / \mathrm{g}$; FT: $7.6(0.3) \%$; mean arterial pressure: 155 (7) $\mathrm{mm} \mathrm{Hg}$ ). In contrast, $30 \mathrm{~min}$

Table 1 Myocardial blood flow

\begin{tabular}{|c|c|c|c|c|c|c|}
\hline & Control & $L-N A M E$ & Indomethacin & $\begin{array}{l}L-N A M E+ \\
\text { Indomethacin }\end{array}$ & Glibenclamide & $\begin{array}{l}\text {L-NAME+} \\
\text { glibenclamide }\end{array}$ \\
\hline $\begin{array}{l}\text { Baseline } \\
\text { Pretreatment } \\
\text { ACh } \\
\text { SNP } \\
\text { Dobutamine }\end{array}$ & $\begin{array}{l}3.8(0.2) \\
5.4(0.5)^{\star} \\
5.5(0.3)^{\star} \\
6.0(0.2)^{\star}\end{array}$ & $\begin{array}{l}3 \cdot 8(0 \cdot 2) \\
1 \cdot 6(0 \cdot 2)^{\star} \\
2 \cdot 7(0 \cdot 2)^{\star} \dagger \\
5 \cdot 1(0 \cdot 4)^{\star} \dagger \\
6 \cdot 1(0 \cdot 2)^{\star} \dagger\end{array}$ & $\begin{array}{l}3.7(0.3) \\
3.5(0.3) \\
5 \cdot 0(0.4)^{\star} \dagger \\
4.8(0.3)^{\star} \dagger \\
5.9(0.2)^{\star} \dagger\end{array}$ & $\begin{array}{l}3.8(0 \cdot 2) \\
1.8(0 \cdot 2)^{\star} \\
2.4(0 \cdot 2)^{\star} \dagger \\
4.9(0 \cdot 3)^{\star} \dagger \\
6.5(0.7)^{\star} \dagger\end{array}$ & $\begin{array}{l}3 \cdot 6(0 \cdot 3) \\
3 \cdot 3(0 \cdot 3) \\
5 \cdot 2(0 \cdot 2)^{\star} \dagger \\
5 \cdot 4(0 \cdot 2)^{\star}+ \\
5.9(0 \cdot 3)^{\star} \dagger\end{array}$ & $\begin{array}{l}3 \cdot 7(0 \cdot 2) \\
1 \cdot 4(0 \cdot 2)^{\star} \\
2 \cdot 4(0 \cdot 2)^{\star} \dagger \\
4 \cdot 8(0 \cdot 2)^{\star} \dagger \\
6 \cdot 1(0 \cdot 6)^{\star} \dagger\end{array}$ \\
\hline
\end{tabular}

Myocardial blood flow $(\mathrm{ml} / \mathrm{min} / \mathrm{g})$ under baseline conditions and after application of acetylcholine (ACh), sodium nitroprusside (SNP), and dobutamine. Values are mean (SD) of the control oup $(n=8)$ and after pretreatment with L-NAME (n $=6$ ) indomethacin $(n=6)$, L-NAME + indomethacin $(n=6)$, glibenclamide $(n=6)$, and L-NAME + glibenclamide $(n=6)$. indomethacin $(\mathrm{n}=6)$, L-NAME + indomethacin

Table 2 Systolic thickening fraction

\begin{tabular}{|c|c|c|c|c|c|c|}
\hline & Control & $L-N A M E$ & Indomethacin & $\begin{array}{l}L-N A M E+ \\
\text { Indomethacin }\end{array}$ & Glibenclamide & $\begin{array}{l}\text {L-NAME+} \\
\text { glibenclamide }\end{array}$ \\
\hline $\begin{array}{l}\text { Baseline } \\
\text { Pretreatment } \\
\text { ACh } \\
\text { SNP } \\
\text { Dobutamine }\end{array}$ & $\begin{array}{l}11.5(0.8) \\
11.8(0.6) \\
11.5(0.7) \\
14.4(0.9)^{\star}\end{array}$ & $\begin{array}{r}11.9(0.5) \\
7.3(0.4)^{\star} \\
7.9(0.4)^{\star}+ \\
8 \cdot 1(0.5)^{\star}+ \\
15 \cdot 1(0.6)^{\star}+\end{array}$ & $\begin{array}{l}11.5(0.8) \\
11.9(0.7) \\
11.5(0.5) \\
11.7(0.5) \\
14.3(0.3)^{\star}\end{array}$ & $\begin{array}{c}11 \cdot 7(0 \cdot 7)^{\star} \\
7 \cdot 3(0 \cdot 3)^{\star} \\
7 \cdot 4(0 \cdot 2)^{\star} \\
7 \cdot 4(0 \cdot 2)^{\star} \\
14 \cdot 4(0 \cdot 4)^{\star}\end{array}$ & $\begin{array}{l}11.9(1.2) \\
11.8(0.9) \\
11.8(0.8) \\
12.0(0.7) \\
14.6(0.7)^{\star}\end{array}$ & $\begin{array}{c}11 \cdot 8(0 \cdot 7)^{\star} \\
6 \cdot 9(0 \cdot 4)^{\star} \\
7 \cdot 0(0 \cdot 3)^{\star} \\
7 \cdot 1(0 \cdot 3)^{\star} \\
15 \cdot 1(0 \cdot 5)^{\star}\end{array}$ \\
\hline
\end{tabular}

Systolic thickening fraction (\%) under baseline conditions and after application of acetylcholine (ACh), sodium nitroprusside (SNP), and dobutamine. Values are mean $(S D)$ of the control group $(n=8)$ and after pretreatment with L-NAME $(n=6)$ indomethacin $(n=6), L=N A M E+$ indomethacin $(n=6)$, glibenclamide $(n=6)$, and L-NAME + glibenclamide $(n=6)$. $\star \mathrm{P}<0.05 v$ baseline; $+\mathrm{P}<0.05 v$ pretreatment.

Table 3 Mean arterial pressure

\begin{tabular}{lllllll}
\hline & Control & L-NAME & Indomethacin & $\begin{array}{l}\text { L-NAME+ } \\
\text { Indomethacin }\end{array}$ & Glibenclamide & $\begin{array}{l}\text { L-NAME } \\
\text { glibenclamide }\end{array}$ \\
\hline Baseline & $120(8)$ & $125(4)$ & $121(5)$ & $130(6)$ & $124(3)$ & $123(4)$ \\
Pretreatment & & $150(5)^{\star}$ & $120(3)$ & $150(6)^{\star}$ & $138(4)^{\star}$ & $153(5)^{\star}$ \\
ACh & $110(8)$ & $138(8)^{\star}+$ & $113(4)^{\star} \dagger$ & $138(5)^{\star} \dagger$ & $130(4)^{\star} \dagger$ & $145(4)^{\star} \dagger$ \\
SNP & $114(9)$ & $145(8)^{\star}$ & $118(3)$ & $144(3)^{\star}$ & $135(3)^{\star}$ & $145(4)^{\star}$ \\
Dobutamine & $135(9)^{\star}$ & $150(5)^{\star}$ & $134(4)^{\star} \dagger$ & $152(5)^{\star}$ & $135(3)^{\star}$ & $151(2)^{\star}$
\end{tabular}

Mean arterial pressure $(\mathrm{mm} \mathrm{Hg})$ under baseline conditions and after application of acetylcholine (ACh), sodium nitroprusside (SNP), and dobutamine. Values are mean (SD) of the control group $(n=8)$ and after pretreatment with L-NAME (n $=6$ ) indomethacin $(n=6)$, L-NAME + indomethacin $(n=6)$, glibenclamide $(n=6)$, and L-NAME + glibenclamide $(n=6)$.

${ }_{\star} \mathrm{P}<0.05 v$ baseline; $+\mathrm{P}<0.05 v$ pretreatment. 


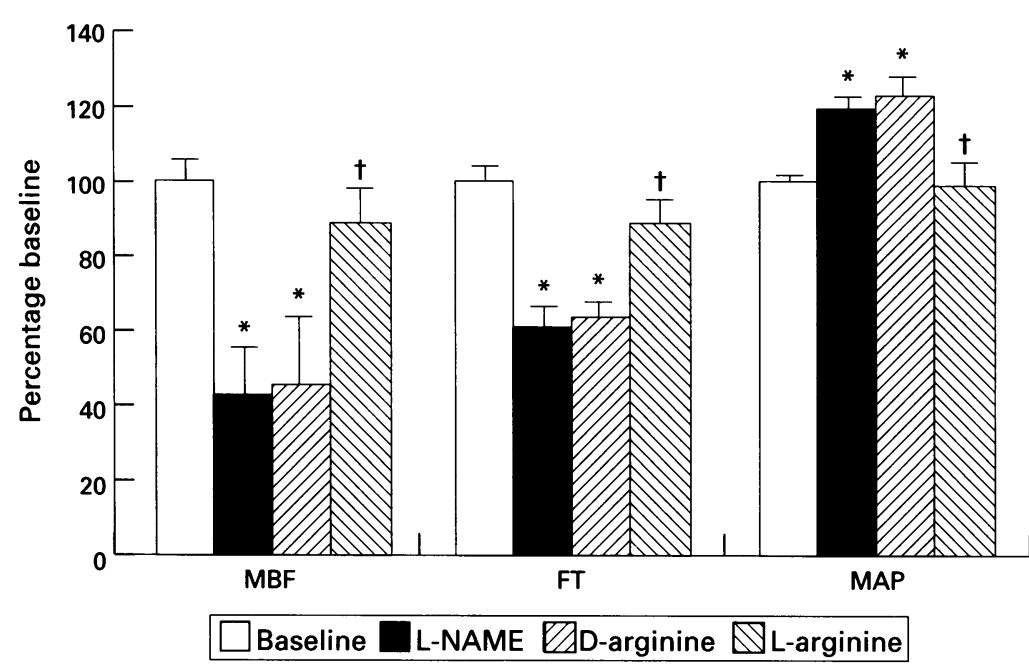

Figure 2 Effects of L-NAME, D-arginine, and L-arginine on myocardial blood flow $(M B F)$, thickening fraction (FT), and mean arterial pressure (MAP) compared with baseline values. Error bars $=S D, n=6$ experiments. $M B F$ and $F T$ were significantly reduced and $M A P$ significantly increased by $L-N A M E\left({ }^{*} P<0.05 v\right.$ baseline $)$. In contrast to $D$-arginine, $L$-arginine revereed the effects of $L-N A M E(+P<0.05 v$ $L-N A M E)$.
SERIES III (INDOMETHACIN GROUP)

Infusion of indomethacin did not change basal myocardial blood flow $(3.5(0.3) \mathrm{ml} / \mathrm{min} / \mathrm{g})$, FT $(11.9(0.7) \%)$, or mean arterial pressure (120 (3) $\mathrm{mm} \mathrm{Hg}$ ).

Pretreatment with indomethacin did not alter the increase in myocardial blood flow caused by acetylcholine $(5(0.4) \mathrm{ml} / \mathrm{min} / \mathrm{g})$, sodium nitroprusside $(4 \cdot 8(0.3) \mathrm{ml} / \mathrm{min} / \mathrm{g})$, or dobutamine $(5.9 \quad(0.2) \mathrm{ml} / \mathrm{min} / \mathrm{g})$. Furthermore, there were no significant changes in FT and mean arterial pressure, as observed in the control group (tables 1-3).

SERIES IV (INDOMETHACIN + L-NAME GROUP) Pretreatment with L-NAME in combination with indomethacin did not further affect basal myocardial blood flow $(1.8(0.2) \mathrm{ml} / \mathrm{min} / \mathrm{g})$, FT $(7 \cdot 3(0 \cdot 3) \%)$, or mean arterial pressure (150 (6) $\mathrm{mm} \mathrm{Hg}$ ) compared to the results obtained after pretreatment with L-NAME alone.

Similarly, the effects of acetylcholine, sodium nitroprusside, and dobutamine on myocardial blood flow, FT, and mean arterial pressure in this series were not significantly different from those obtained in the series with L-NAME alone (tables 1-3).

after continuous intravenous administration of L-arginine, there was a reversal of the effects of L-NAME (myocardial blood flow: $3 \cdot 4(0 \cdot 3)$ $\mathrm{ml} / \mathrm{min} / \mathrm{g} ; \mathrm{FT}$ : $10.6(0.7) \%$; mean arterial pressure: 125 (7) $\mathrm{mm} \mathrm{Hg}, \mathrm{P}<0.05$; fig 2).

Following pretreatment with L-NAME, the effect of acetylcholine on myocardial blood flow was reduced $(P<0.05)$ and myocardial blood flow remained below the baseline value $(2 \cdot 7(0 \cdot 2) \mathrm{ml} / \mathrm{min} / \mathrm{g}, \Delta=-27(7) \%)$. FT and mean arterial pressure, however, were not significantly altered by acetylcholine (7.9 (0.4)\%; 138 (8) $\mathrm{mm} \mathrm{Hg}$ ).

There was no significant difference in the response of myocardial blood flow, FT, and mean arterial pressure to sodium nitroprusside in the L-NAME pretreated group compared to the control group.

As with the effects observed in the control group, dobutamine increased both myocardial blood flow and FT in the L-NAME pretreated group, whereas mean arterial pressure was unaltered (figs 1 and 3, tables 1-3).

There was no significant difference in the double product obtained with administration of dobutamine before compared with after pretreatment with L-NAME (baseline + dobutamine: 65.2 (6) $\mathrm{mm} \mathrm{Hg} \times$ beats $/ \mathrm{min} /$ 104; L-NAME + dobutamine: $66 \cdot 3(4 \cdot 6) \mathrm{mm}$ $\mathrm{Hg} \times$ beats $/ \mathrm{min} / 10^{4}$; NS).

\footnotetext{
Figure 3 Myocardial blood flow (MBF) under baseline conditions, after pretreatment with pretreatment with application of acetylcholine (ACh), sodium nitroprusside (SNP), and dobutamine (Dobu) in 6 rats. Error bars $=S D, n$ $=8$ experiments. ${ }^{\star} P<$ 0.05 v baseline; $+P<0.05$ $v$ pretreatment with
} $L-N A M E$.

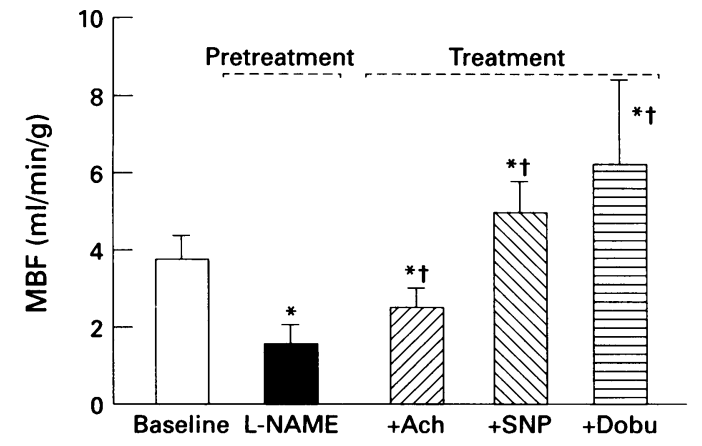

SERIES V (GLIBENCLAMIDE GROUP)

Intravenous administration of glibenclamide did not significantly alter myocardial blood flow (3.3 (0.3) $\mathrm{ml} / \mathrm{min} / \mathrm{g})$ and FT $(11.8$ $(0.9) \%)$; the drug caused a small though statistically significant increase in mean arterial pressure (138 (4) $\mathrm{mm} \mathrm{Hg}$ ).

In glibenclamide pretreated animals, the effects of acetylcholine, sodium nitroprusside, and dobutamine on myocardial blood flow, FT, and mean arterial pressure observed $30 \mathrm{~s}$ after bolus administration were not significantly different from the values obtained in the control group (tables 1-3).

SERIES VI (GLIBENCLAMIDE + L-NAME GROUP) Addition of glibenclamide did not alter the effect of L-NAME on myocardial blood flow $(1.4(0.2) \mathrm{ml} / \mathrm{min} / \mathrm{g})$, FT $(6.9(0.4) \%)$, or mean arterial pressure $(153(5) \mathrm{mm} \mathrm{Hg})$.

The effects of acetylcholine, sodium nitroprusside, and dobutamine on myocardial blood flow, FT, and mean arterial pressure after pretreatment with L-NAME + glibenclamide were not different from those obtained with L-NAME alone (tables 1-3).

\section{Discussion}

Our data show that the increase in myocardial blood flow induced by the positive inotropic action of dobutamine is not attenuated by inhibiting EDRF synthesis (L-NAME), prostaglandin synthesis (indomethacin), or the ATP sensitive potassium channels (glibenclamide). We can therefore assume that endothelium dependent relaxing factors are not required for the physiological adaptation of myocardial blood flow to myocardial energy demands in the rat heart. 
METHODOLOGICAL CONSIDERATIONS AND LIMITATIONS OF THE STUDY

Myocardial metabolic demands were increased with dobutamine. This drug acts directly on the myocardium, predominantly by $\beta_{1}$ receptor stimulation, and exerts only minor chronotropic or vasodilator effects, ${ }^{21}$ though it has been shown that dobutamine may induce the release of EDRF through $\beta_{1}$ receptors in rat microvessels. ${ }^{22}$ Thus the dobutamine induced increase in myocardial blood flow primarily reflects adaptation to augmented myocardial metabolic demands.

All drugs used in this study were given intravenously. In contrast to indomethacin and L-NAME, which can be given as a bolus to achieve full effects for several hours, glibenclamide as well as D- and L-arginine had to be given by continuous intravenous infusion to accomplish long lasting effects. Since intracoronary administration of the drugs was not possible in this study, brief transient systemic effects after intravenous bolus administration of acetylcholine and sodium nitroprusside could not be completely prevented-for example, immediately after administration of the vasodilators, an instantaneous brief decline in systemic blood pressure was observed. Since haemodynamic measurements were recorded continuously throughout all the experiments, we were able to determine the exact time of recovery of the mean arterial blood pressure, which in all experiments was 15-20 seconds after the administration of the vasodilators. Therefore, myocardial blood flow and systolic thickening fraction were determined $30 \mathrm{sec}-$ onds after administration of acetylcholine, sodium nitroprusside, and dobutamine, when mean arterial blood pressure was no longer affected.

EDRF

A substantial role for EDRF in the regulation of vascular tone is well established. ${ }^{12}$ Acetylcholine causes vasodilatation in normal arteries, but after removal of endothelium or in atherosclerotic vessels with destruction of endothelial cells, acetylcholine may provoke vasoconstriction. ${ }^{1323}$ However, the significance of EDRF as a vasodilator in relation to other vasodilating factors has not yet been defined. Several investigators have described an impaired EDRF dependent vasodilatation after short episodes of ischaemia. ${ }^{11}{ }^{24}$ In these studies, however, the maintenance of coronary reserve was not investigated. Other workers have shown that a decrease in myocardial blood flow in models of repetitive short term ischaemia can be reversed by numerous positive inotropic interventions and they therefore suggested that the reduction in blood flow under these conditions is a result of diminished metabolic demands. ${ }^{25}$ Interestingly, after inhibition of EDRF synthesis by L-NAME, adenosine production is increased during reactive hyperaemia and may thus compensate for the loss of EDRF activity. ${ }^{26} 27$

Recently, it has been shown in a dog model that inhibition of EDRF synthesis by the arginine analogue $\mathrm{N}-\omega$-nitro-L-arginine (L-NNA) inhibits the endothelium dependent vasodilatation induced by acetylcholine and decreases reactive hyperaemia; however, it does not attenuate the rise in coronary perfusion induced by exercise. ${ }^{28}$ These findings strongly support our results showing that EDRF is not essential for the adaptation of myocardial blood flow to increased metabolic demands. However, inhibition of nitric oxide formation in a dog exercise model with a coronary artery stenosis resulted in a decrease in myocardial blood flow in the ischaemic area during exercise. ${ }^{29}$ Therefore, it can be speculated that EDRF is of greater importance for the maintenance of coronary reserve under pathological conditions such as ischaemia, presumably because of the parallel impairment of other vasodilating systems. It is also thought that different vasoregulatory systems have different major sites of action along resistance vessels. ${ }^{30}$

\section{INHIBITION OF EDRF SYNTHESIS}

In the present study, the $\mathrm{L}$-arginine analogue L-NAME was used to block nitric oxide production. This compound was intentionally chosen as an inhibitor of nitric oxide formation in this study because-in contrast to other inhibitors of EDRF synthesis-L-NAME also blocks muscarinic receptors. Thus an interaction of acetylcholine with muscarinic receptors leading to vasoconstriction cannot falsify the results.

L-NAME caused a prolonged decrease in myocardial blood flow and a marked rise in systemic blood pressure and thus an increase in coronary resistance. The dose of L-NAME used in this study was similar to the doses used in other studies, ${ }^{56}$ and provoked a nearly complete inhibition of EDRF synthesis, as shown by the markedly reduced ability of acetylcholine to increase myocardial blood flow despite the increase in mean arterial pressure following treatment with L-NAME.

To further demonstrate a specific inhibitory effect of L-NAME on EDRF synthesis, Dand L-arginine were given after pretreatment with L-NAME. Intravenous administration of L-arginine, but not $\mathrm{D}$-arginine, significantly reversed the effects of L-NAME on myocardial blood flow, systolic thickening fraction, and mean arterial blood pressure, showing that L-NAME specifically inhibited NO synthesis in this study.

After pretreatment with L-NAME, the effect of the endothelium dependent vasodilator acetylcholine was significantly reduced, although not completely inhibited. This indicates that acetylcholine causes vasodilatation not only through EDRF but also through other substances such as EDHF. This observation is in accordance with data of other investigators: for example, it has been shown that after inhibition of EDRF with L-NMMA both bradykinin and acetylcholine can still exert vasorelaxing effects. ${ }^{27}{ }^{31-33}$

L-NAME reduced myocardial thickening fraction in our experiments. This might be due to an increased afterload and to the reduction in myocardial blood flow. This interpretation 
is in agreement with results obtained with isolated myocytes in which contractile function was not primarily affected by L-NAME..$^{27} 34$

\section{PROSTAGLANDINS}

Endothelial cells are the main source of production of prostacyclin, a powerful vasodilator and inhibitor of platelet aggregation. ${ }^{35}$ Prostacyclin, however, seems to have an almost negligible effect on basal vascular tone. Aspirin, an inhibitor of cyclooxygenase, has no effect on systemic blood pressure. Furthermore, prostacyclin contributes little to endothelium dependent vasorelaxation. ${ }^{36}$ However, prostacyclin induced vasodilatation could become more important where there is reduced EDRF synthesis. In this study, inhibition of prostaglandin synthesis did not affect either endothelium dependent or endothelium independent vasodilatation. The increase in myocardial blood flow and regional myocardial function after administration of dobutamine was likewise not influenced by pretreatment with indomethacin. Thus the observation of other investigators that prostacyclin does not contribute to basal vascular tone ${ }^{3637}$ can be extended to the condition of diminished EDRF production, as shown in this study.

\section{EDHF AND ATP SENSITIVE POTASSIUM \\ CHANNELS}

The endothelium releases a hyperpolarising factor (EDHF) which has not yet been identified. Acetylcholine can induce an endothelium dependent relaxation of smooth muscle cells. This effect is mediated by a diffusible substance and inhibited by substances blocking ATP sensitive potassium channels, such as glibenclamide. In the present experiments, inhibition of ATP sensitive potassium channels by glibenclamide in effective doses, ${ }^{38}$ both alone and in combination with inhibition of EDRF synthesis by L-NAME, did not influence endothelium dependent vasodilatation. The increase in myocardial blood flow caused by application of dobutamine was not impaired after blockade of the ATP sensitive potassium channels. According to these results, activation of the ATP sensitive potassium channels - and hence of EDHF-is not required for the adaptation of myocardial blood flow to the actual metabolic demand. However, we did not investigate the influence of inhibition of $\mathrm{K}_{\mathrm{Ca}}$ channels which may also be involved in the regulation of EDHF in rat microvessels. ${ }^{39}$

The results of our study show that despite inhibition of EDRF synthesis, prostaglandin synthesis, and ATP sensitive potassium channels, adequate adaptation of myocardial blood flow to increased metabolic demands following $\beta_{1}$ receptor stimulation is still maintained. Therefore, it can be concluded that, in the rat heart, local metabolic regulation of coronary flow under physiological conditions is not dependent on these endothelial vasodilators. Further studies are necessary to evaluate the significance of these findings for the physiology of man.
We thank Helga Adler and Rudolf Dussel for their expert technical assistance.

Parts of this study have been presented at the 65 th Scientific Sessions of the American Heart Association 1992. This study was supported by a grant from the Deutsche was supported by a grant from the Deutsche 320 "Herzfunktion und ihre Regulation", Ruprecht-KarlsUniversity Heidelberg, Germany

1 Furchgott RF, Zawadzki JY. The obligatory role of endothelial cells in the relaxation of arterial smooth muscle by acetylcholine. Nature 1980;288:373-6.

2 Lüscher TF, Richard V, Tanner FC. Endothelium-derived relaxing factors and their role in the coronary circulation. Trends Cardiovasc Med 1991;1:179-84.

3 Palmer RMJ, Ferrige AG, Moncada S. Nitric oxide release accounts for the biological activity of endotheliumderived relaxing factor. Nature 1987;327:524-6.

4 Palmer RMJ, Rees DD, Ashton DS, Moncada S. L-arginine is the physiological precursor for the formation of nine is the phy in endothelium-dependent relaxation. Biochem Biophys Res Commun 1988;153:1251-6.

5 Rees DD, Palmer RJM, Schulz R, Hodson HF, Moncada $S$. Characterization of three inhibitors of endothelial nitric oxide synthase in vitro and in vivo. Br f Pharmacol nitric oxide synthase

6 Gardiner SM, Compton AM, Kemp PA, Bennett T Regional and cardiac hemodynamic effects of $\mathrm{N}^{\mathrm{G}}$-nitroL-arginine methyl ester in conscious, Long Evans rats. $B$ F Pharmacol 1990;101:625-31.

7 Vane JR, Ânggard EE, Botting RM. Regulatory functions of the vascular endothelium. $N$ Engl $f$ Med 1990;323 27-35.

8 Yang BC, Nichols WW, Mehta JL. Cardiac effects of acetylcholine in rat hearts: role of endothelium-derived relaxing factor and prostaglandins. Am $\mathcal{F}$ Physiol 1993; 246:H1388-93.

9 Suzuki H, Chen G. Endothelium derived hyperpolarizing factor (EDHF): an endogenous potassium channel activator. News Physiol Sci 1990;5:212-5.

10 Narishige T, Egashira K, Akatsuka Y, Katsuda Y, Numaguchi $K$, Sakata $M$, et al. Glibenclamide, a putative ATP-sensitive $\mathrm{K}^{+}$channel blocker, inhibits coronary autoregulation in anesthetized dogs. Circ Res 1993;73: autoreg $771-6$.

$11 \mathrm{Ku} \mathrm{DD}$. Coronary vascular reactivity after acute myocardial ischemia. Science 1982;218:576-8.

12 Headrick JP, Angello DA, Berne RM. Effects of brief coronary occlusion and reperfusion on porcine coronary artery reactivity. Circulation 1990;82:2163-9.

13 Shiromokawa H, Vanhoutte PM. Impaired endothelium dependent relaxation to aggregating platelets and related vasoactive substances in porcine coronary arteries in hypercholesteremia and atherosclerosis. Circ Res 1989; 64:990-1.

14 Zeiher AM, Drexler H, Wollschlager H, Just $H$ Endothelial dysfunction of the coronary microvasculature is associated with impaired coronary blood flow regulation in patients with early atherosclerosis. Circulation 1991;84:1984-92.

15 Vanhoutte PM, Houston DS. Platelets, endothelium and vasospasm. Circulation 1985;72:728-34.

16 Berne RM. The role of adenosine in the regulation of coronary blood flow. Circ Res 1980;47:807-13.

17 Cunningham LD, Brecher $P$, Cohen $R$. Platelet-derived growth factor receptors on macrovascular endothelial cells mediate relaxation via nitric oxide in the rat aorta. $\mathscr{f}$ Clin Invest 1992;89:878-82.

18 Aukland K, Bower BF, Berliner RW. Measurement of local blood flow with hydrogen gas. Circ Res 1964;14:164-87.

19 Tiefenbacher CP, Zimmermann R, Parekh N, Amann K Tillmanns $\mathrm{H}$, Rauch B, et al. Preservation of myocardia blood flow by calcium antagonists does not preven attenuation of regional myocardial function after repetitive brief periods of myocardial ischemia in the rat heart. Eur Heart $\mathcal{f}$ 1995;16:1057-62.

20 Hartley CJ, Latson LA, Michael LH, Seidel CL, Lewis RM, Entman ML. Doppler measurement of myocardia thickening with a single epicardial transducer. $A m$ Physiol 1983;245:H1066-72.

21 Tuttle RR, Mills J. Dobutamine: development of a new catecholamine to selectively increase cardiac contractility. Circ Res 1975;36:185-96.

22 Graves J, Poston L. Beta-adrenoceptor agonist mediated relaxation of rat isolated resistance arteries: a role for endothelium and nitric oxide. Br $\mathcal{F}$ Pharmacol 1993;108: endothe

23 Vita JA, Treasure CB, Nabel EG, McLenachan JM, Fish RD, Yeung AC, et al. Coronary vasomotor response to $\mathrm{RD}$, Yeung AC, et al. Coronary vasomotor response to
acetylcholine relates to risk factors for coronary artery

24 Gross GJ, O'Rourke ST, Pelc LR, Warltier DC. Myocardial and endothelial dysfunction after multiple,
brief coronary occlusions: role of oxygen radicals. $A m \mathcal{f}$ brief coronary occlusions: role of oxygen radicals.

25 Bolli R. Mechanisms of myocardial stunning. Circulation 1990;82:723-38.

26 Kostic MM, Schrader J. Role of nitric oxide in reactive hyperemia of the guinea pig heart. Circ Res 1992;70: 208-12.

27 Brady AJ, Warren JB, Poole-Wilson PA, Williams TJ, Harding SE. Nitric oxide attenuates cardiac myocyt contraction. Am $\mathcal{F}$ Physiol 1993;265:H176-82. 
28 Altmann JD, Kinn J, Duncker DJ, Bache RJ. Effect of inhibition of nitric oxide formation on coronary blood flow during exercise in the dog. Cardiovasc Res 1994;28: 119-24

29 Duncker DJ, Bache RJ. Inhibition of nitric oxide production aggravates myocardial hypoperfusion during exercise in the presence of a coronary artery stenosis. Circ Res 1994;74:629-40.

30 Jones CJ, Kuo L, Davis MJ, DeFily DV, Chilian WM. Role of nitric oxide in the coronary microvascular response to corction 1995;91:1807-13.

31 Cowan CL, Cohen RA. Two mechanisms mediate relaxation by bradykinin of pig coronary artery: NO-dependent and -independent responses. Am $\mathcal{F}$ Physiol 1991; 261:H830-5.

32 Dohi J, Thiel MA, Bühler FR, Lüscher TF. Activation of endothelial $\mathrm{L}$-arginine pathway in resistance arteries. Hypertension 1990;15:170-9.

33 Garland CJ, McPherson GA. Evidence that nitric oxide does not mediate the hyperpolarization and relaxation to acetylcholine in the rat small mesenteric artery. $\mathrm{Br} f$ Pharmacol 1992;105:429-35.

34 Garcia JL, Fernandez N, Garcia Villalon AL, Monge L,
Gomez B, Dieguez G. Effects of nitric oxide synthesis inhibition on the goat coronary circulation under basal conditions and after vasodilator stimulation. $\mathrm{Br} f$ Pharmacol 1992;106:563-7.

35 Moncada S, Gryglewski R, Bunting S, Vane R. An enzyme isolated from arteries transforms prostaglandin endoperoxides to an unstable substance that inhibits platelet aggregation. Nature 1976;263:663-5.

36 Tschudi M, Richard V, Bühler R, Lüscher TF. Importance of endothelium-derived nitric oxide in porcine coronary resistance arteries. Am $\mathcal{f}$ Physiol 1991;260: H13-20.

37 Shimokawa H, Vanhoutte PM. Dietary omega 3 fatty acids and endothelium-dependent relaxations in porcine coroand endothelium-dependent relaxations in porcin

38 Toombs CF, Moore TI, Shebuski RJ. Limitation of infarct size in the rabbit by ischemic preconditioning is reversible with glibenclamide. Cardiovasc Res 1993;27 617-22.

39 Bauernsachs J, Hecker M, Busse R. Display of the characteristics of endothelium-derived hyperpolarizing factor by a cytochrome P450 derived arachidonic acid metabolite in the coronary microcirculation. Br f Pharmacol 1994, 113:1548-53. 